\title{
FIRST RECORD OF A PARATYDEIDAE (ACARI, PROSTIGMATA) \\ IN SOUTH AMERICA WITH DESCRIPTION OF SCOLOTYDAEUS CORTICICOLA SP.N.
}

\author{
Carlos H.W. Flechtmann ${ }^{2}$
}

\begin{abstract}
Scolotydaeus corticicola sp.n. is described, from the bark of an eucalyptus tree, from Piracicaba, São Paulo, Brazil.

KEY WORDS. Acarina, Paratydeidae, Scolotydaeus, first record, São Paulo, Brazil
\end{abstract}

Mites of family Paratydeidae have been found in soil in Europe, North and Central America and in South Africa (BERLESE, 1910; BAKER, 1949, 1950; THERON et al., 1969; KRANTZ, 1978). In this paper a species collected from bark, one meter above the soil, is described.

\section{Scolotydaeus corticicola, sp.n.}

Figs 1-11

Female. Dorsum (Fig. 1). Body elongate, divided into three sections by transverse sutures. The anterior section, propodosoma, $109 \mu \mathrm{m}$ length, triangular in shape, has two pairs of eyes; one pair of relatively long sensory setae (bothridia); two pairs of short, simple, slightly lanceolate, setae, one pair anterior and one pair posterior to the sensory setae; one pair of minute peg-like setae situated on the region dorsolaterally to leg I. Anteromedially, chambered peritremes. A narrow longitudinal plate, like a crista metopica, slightly sclerotized, extends mesally along most of the length of the propodosoma.

The middle section, $110 \mu \mathrm{m}$ long, $197 \mu \mathrm{m}$ wide, is roughly rectangular in shape, presents one transverse row of four setae, the inner pair short and the outer relatively long; and one pair of rounded areas, function unknown.

The remaining of the body (hysterosoma), $241 \mu \mathrm{m}$ long, bears five pairs of short medially situated, slightly lanceolate, setae and two pairs of posterolateral long setae; two pairs of rounded areas. Cuticle finely striated longitudinally.

Venter (Figs 2, 5). Transverse sutures not discernible ventrally; coxae arranged in two groups, fused to body, forming slightly sclerotized apodemes. One pair of vents al setae, situated in the area between coxae III. Genital opening

1) Desenvolvido com auxilio do CNPq.

2) Departamento de Zoologia, Escola Superior de Agricultura Luiz de Queiroz, Universidade de São Paulo, 13418-900 Piracicaba, São Paulo, Brasil. 


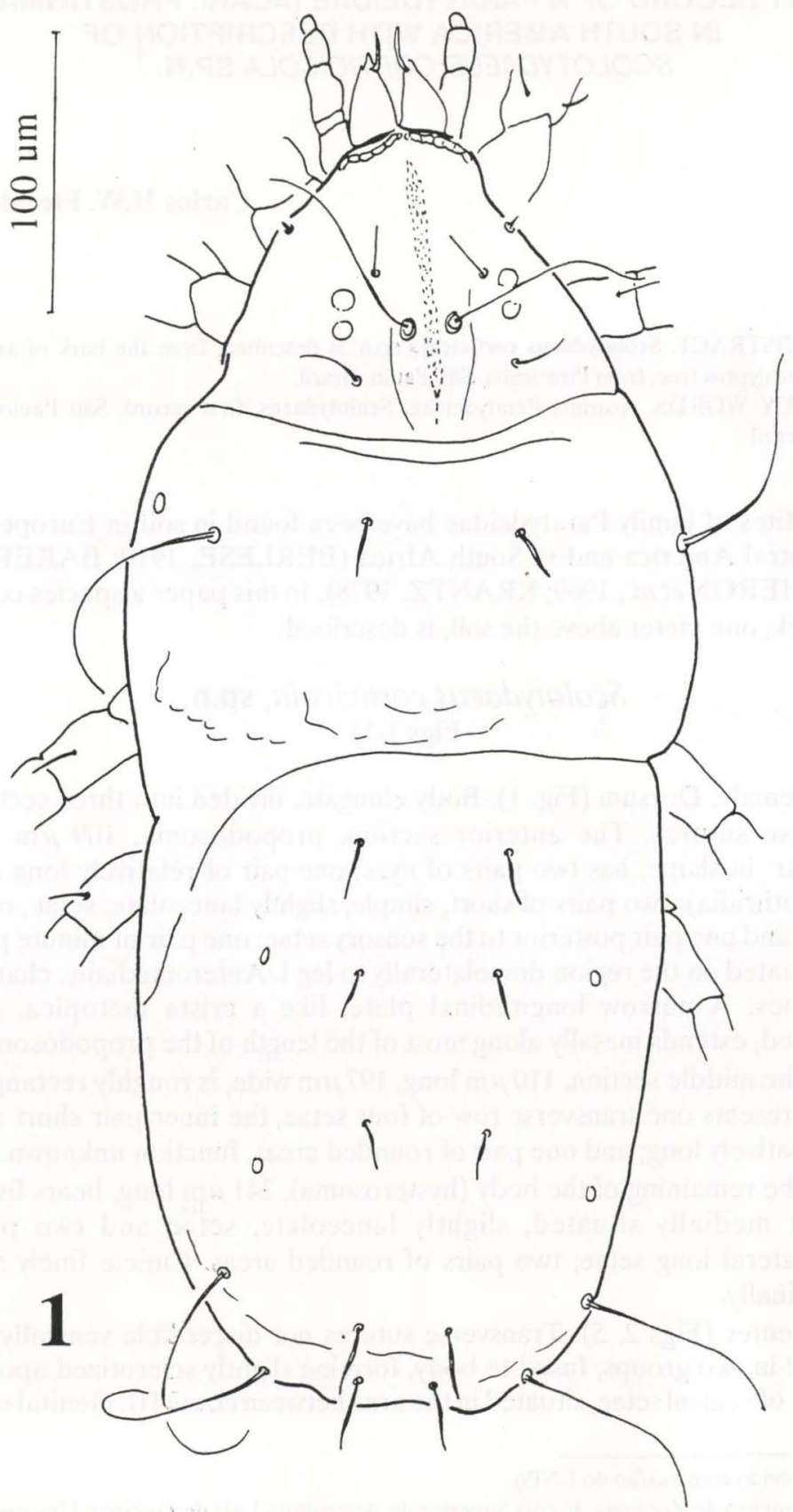

Fig. 1. Scolotydaeus corticicola, sp.n., female. Dorsal aspect. 
longitudinal; genital covers with nine pairs of euginital setae; three pairs of internal ellyptic suckerlike structures. Six pairs of paragenital setae surround the genital area. Anal opening situated posteriorly, with two pairs of euanal setae and two pairs of paranal setae; lateral to anterior pair of paranals one pair of rounded areas. Cuticule finely striated longitudinally.
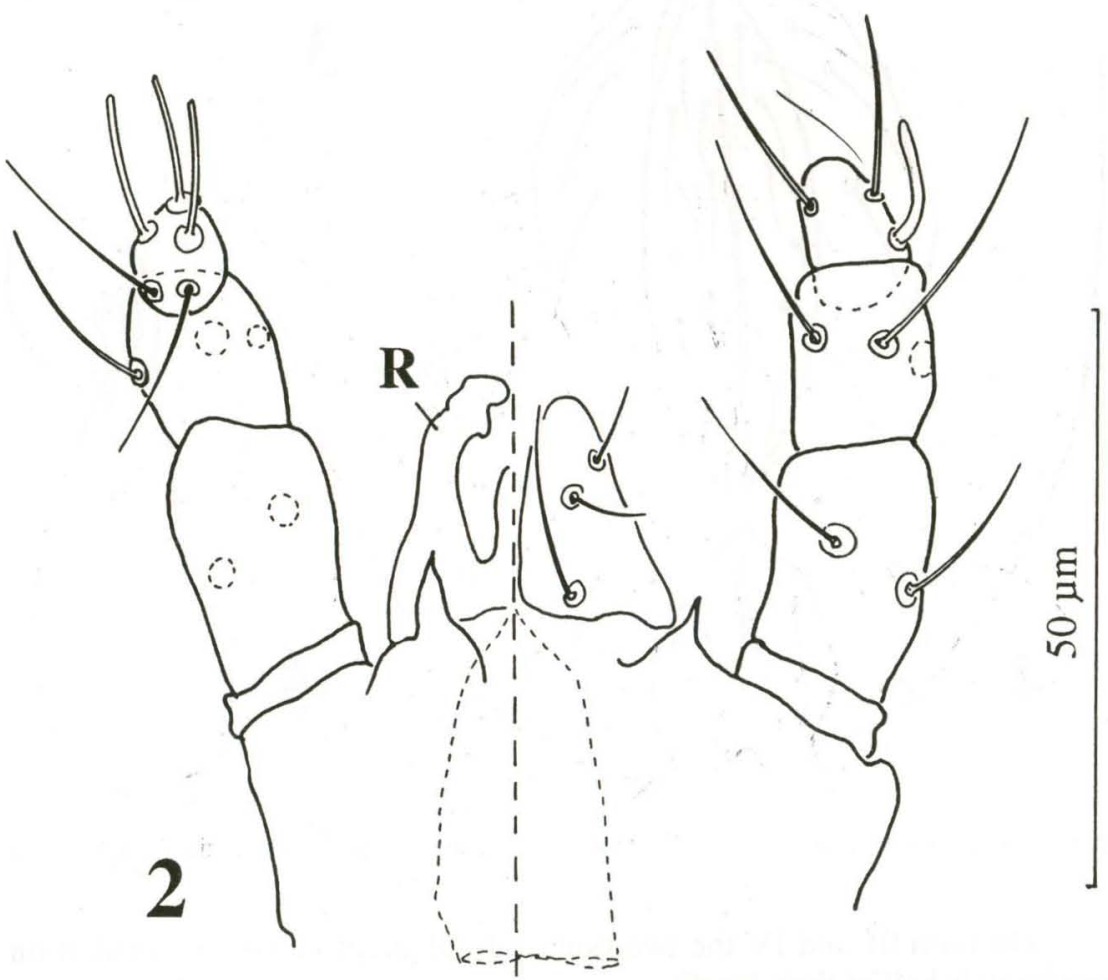

Fig. 2. Scolotydaeus corticicola, sp.n., female. (2) Gnathosoma, ventral view; left side, ventral aspect of palpus; right side, dorsal aspect of palpus; (R) rutella-like structure.

Legs (Figs 6-11). All legs consist of six segments; femora I and IV divided into a basi and telofemur. All tarsi with two claws and a small clawlike empodium. Legs sparsely haired with simples and rodlike setae and with a delicate reticulate-punctuate pattern. With the rodlike setae in parentheses, the leg setae formulae, from coxae to tarsi, are:

Leg I: $3-0-3+3-7(1)-7(1)-6(8)$

Leg II: $3-1-3-4(1)-4(1)-7(1)$

Leg III: $2-1-1+1-2-2(1)-6$

Leg IV: $2-0-1+2-3-3-5$ 
Tarsi I and II and tibiae II and III present, each, dorsally, a pair of setae composed of one simple and one rodlike, whose bases are aproximate and/or adjoining, like the duplex setae in the Tetranychidae.

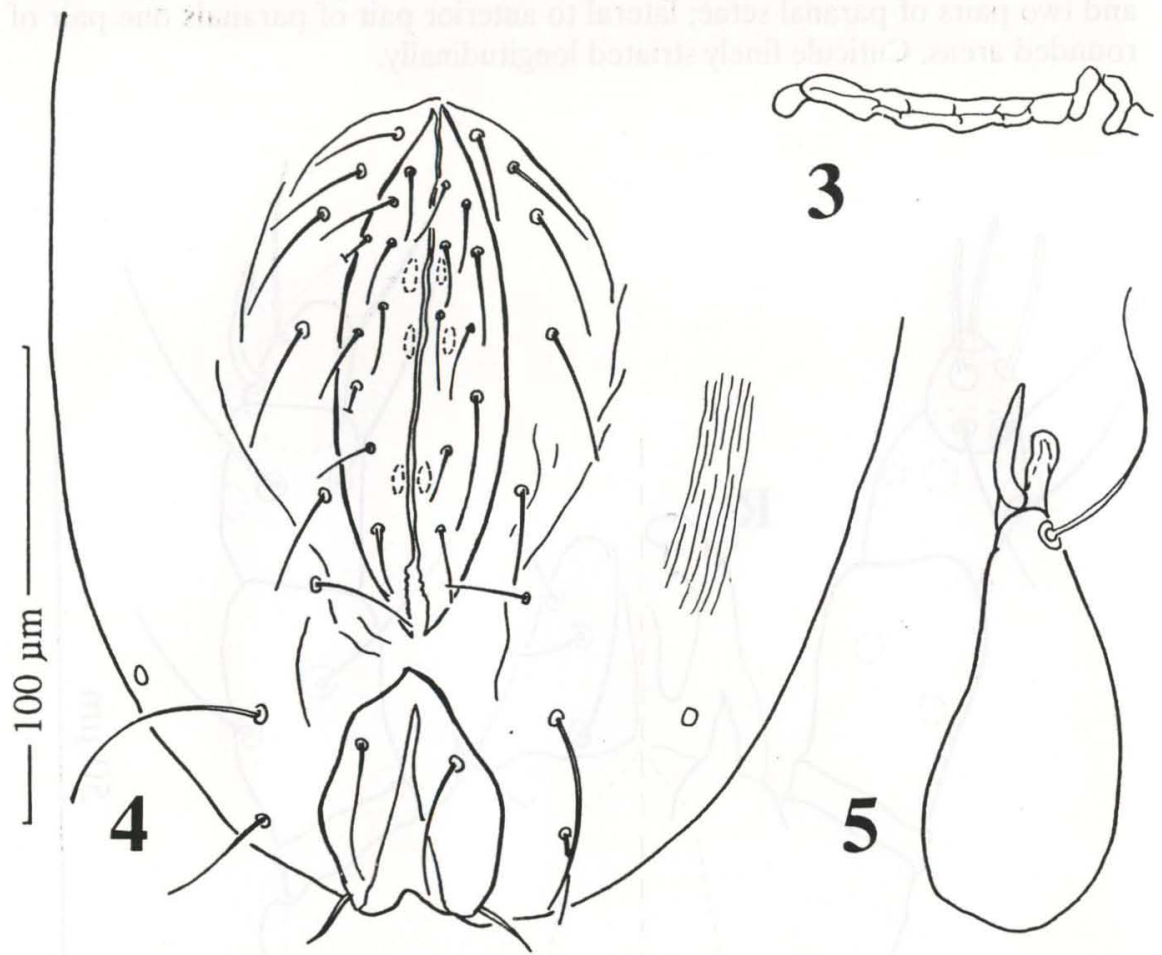

Figs 3-5. Scolotydaeus corticicola, sp.n., female. (3) peritreme; (4) genito-anal region; (5) chelicera.

On tarsi III and IV the two ventral distal simple setae are divided on aproximately half of their length.

Gnathosoma (Figs 2, 5). Palpi four segmented; ventrally the palptarsus bears two simple and two rodlike setae; terminally one rodlike seta and dorsally two simple setae and one solenidion. Palptibiae with two dorsal and one lateral simple setae; palp genua with two dorsal simple setae; trochantera without setae.

The venter of gnathosoma presents a rutella structure. Three pairs of ventral gnathosomal setae. Cheliceral bases apparently not fused; movable digit an elongate blade; fixed digit reduced. Chelicera with a strong dorsal seta.

Material studied. Holotype female, from Eucalyptus bark, approximately one meter above the surface of the soil, Piracicaba, São Paulo, Brazil, October 01, 1992 (I. Delalibera leg). In the author's collection at Departamento de Zoologia, Universidade de São Paulo, Escola Superior de Agronomia (ESALQ), Piracicaba, São Paulo, Brazil.

Remarks. S. corticicola is the second species in the genus; it differs from 

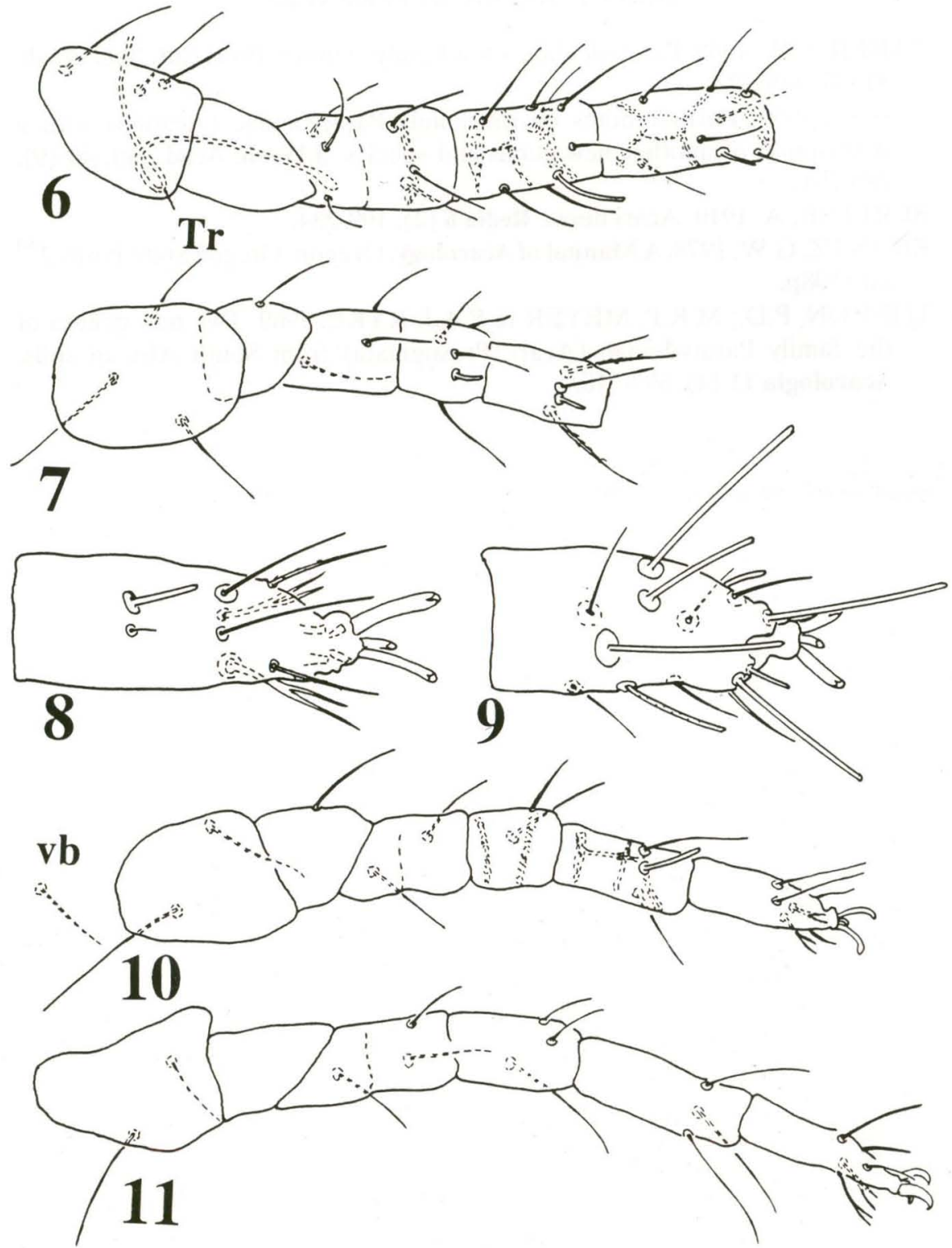

Figs 6-11. Scolotydaeus corticicola, sp.n., female. (6) Leg I, coxa-tibia, (Tr) trachea; (7) leg II, coxa-tibia; (8) tarsus II; (9) tarsus I; (10) Leg III, (vb) ventral body seta; (11) Leg IV.

S. bacillus Berlese in presenting only one pair of dorsolateral peglike setae on the propodosoma; two pairs of eyes; and in the leg and genital setal pattern.

The specific designation, corticicola, means bark inhabitant. 


\section{BIBLIOGRAPHIC REFERENCES}

BAKER, E.W. 1949. Paratydeidae, a new family of mites. Proc. Ent. Soc. Wash. 51 (3): 119-122.

- 1950. Further notes on the family Paratydeidae (Acatina) with a description of another new genus and species. J.Wash. Acad. Sci. 40 (9): 289-291.

BERLESE, A. 1910. Acari nuovi. Redia 6 (2): 199-234.

KRANTZ, G.W. 1978. A Manual of Acarology. Oregon, Oregon State Univ. $2^{\text {nd }}$ ed., 508p.

THERON, P.D.; M.K.P. MEYER \& P.A.J. RYKE. 1969. Two new genera of the family Paratydeidae (Acari, Prostigmata) from South African soils. Acarologia 11 (4): 697-710.

Recebido em 30.VI.1993; aceito em 13.VIII.1993. 